\title{
ATUALIZAÇÄO
}

\section{BRUCELLA CANIS - NOVO AGENTE DE BRUCELOSE CANINA}

\author{
L. Barg*, A.M. Godoy*e J.N. Peres*
}

A bibliografia referente à brucelose canina por Brucella canis já è relativamente numerosa, apesar de ter ela sido descrita há menos de dez anos.

A susceptibilidade do cão às três espécies clássicas de Brucella é conhecida de longa data, porém o interesse pelo estudo da brucelose canina só foi despertado a partir das observações de CARMICHAEL ${ }^{3}$.

Casos de doença por Brucella canis, na tural ou adquirida acidentalmente em laboratório, tèm sido descritas, demonstrando um comportamento similar ao das espécies clás. sicas de Brucella, quanto ao seu potencial patogénico para o homem.

$$
\text { CARMICHAEL }{ }^{3}, \text { MOORE \& }
$$
DENNETT ${ }^{31}$ e TAUL, POWELL \&: $B A K E R^{4}$ I, investigaram a causa do aborto epizoótico que era muito freqüente entre os caẽs de raça "Beagle", em diversas regiões dos Estados Unidos. Isolaram de tecidos fetais, corrimento vaginal, linfonodos e do sangue, urn microorganismo de forma cocobacilar, Gram negativo, que na base de suas propriedades culturais, bioquímicas e sorológicas, foi classificado no gênero Brucella, sem contudo ser identificado como pertencente às espécies já conhecidas. MOORE \& BENNETT ${ }^{31}$ denominaram provisoriamente a bactéria por eles isolada como "Brucella canis" apesar de reconhecerem que sua posição taxonômica deveria ainda ser estudada com mais detalhes.

CARMICHAEL \& KENNEY ${ }^{7}$ diagnosticaram a doença em mais de 800 cães oriundos de 38 Estados da América do Norte. Verificaram que a brucelase canina era caracterizada por linfadenite e esplenite, mortes embrionárias primárias ou abortos precoces não detectados, e aborto evidente a os 45.55 dias de gestação, com prolongada descarga vaginal. Nos machos infectados observaram epididimite, dermatite do escroto $e$ atrofia testicular, freqüentemente unilateral, podendo eles se tornar estéreis. A bacteriemia persistente com duração de um ano era um fato de observação comum. $\mathrm{Na}$ ausência de sintomas clínicas, a infecção era detectada pelo teste de soro-aglutinação. Tendo observado a grande disseminação da doença nas criações de "Beagles" e admitindo a possibilidade de infecção humana, a amostra isolada e designada como RM6-66 foi enviada a especialistas, os quais verificaram características semelhantes aos microorganismos do gênero Brucella, porém com pequenas diferenças. Essa amostra foi designada como espécie tipo, e depositada na "American Culture Collection", com o n? ATTC-23.365. Sugeriram o nome de Brucella canis para o microorganismo isolado do cão, sujeito à aprovação final do "Subcommittee on Taxonomy of Brucella of the International Committee on Bacteriological Nomenclature". Verificaram que 99\% dos casos de aborto ocorrem em animais da raça "Beagle", e que os soros dos cães com títulos aglutinantes para Brucella canis não davam reações cruzadas com Brucella abortus. Não observaram até a época do trabalho, infecção humana natural, e nem em técnicos de laboratório que estiveram em contato com o germe por mais de um ano. Observaram que as alterações clínicas e patológicas são semelhantes às que ocorrem em outras espécies naturalmente infectadas com outras Brucella, porém em cães é uma doença benigna e não mortal.

\footnotetext{
Trabalho do Lats de Bact de Zoonoses. Dept. Microbiologia ICB/UFMG
}

Recebido para publicação em 25.5.1977 
DIAZ, JONES \& WILSON ${ }^{10}$ estudaram as relações antigênicas entre o microorga nismo causador do aborto canino e as outras espécies de Brucella nas suas fases lisa e rugosa, verificando que aquele era semeThante às cepas rugosas de Brucella abortus, Brucella melitensis e Brucella ovis, e diferente das amostras lisas. Observaram que desse germe não se consegue isolar a endotoxina-lipopolissacáride associada com o aglutinigênio das brucelas lisas, o que veio reforçar a proposição de CARMICHAEL \& BRUNER $^{5}$, para a designação da nova espécie, como "Brucella canis". A bactéria tem aproximadamente os miesmos antígenos superficiais das colonias rugosas de Brucella e dá pequena ou nenhuma reação cruzada com brucelas lisas.

Os estudos taxonômicos do agente do aborto canino foram realizados por JONES e cols. $^{24}$, que compararam esse microorganismo com as outras espécies de Brucella e com a Bordetella bronchiseptica; chegaram também à conclusão de que ele se enquadra no gênero Brucella, baseando-se em suas características culturais, bioquímicas e sorológicas. Aproxima-se mais da Brucella suis biotipo 3, sem contudo oxidar o eritritol. Por outro lado a $B$. canis é mais sensível à fucsina básica que a $B$. suis biotipo 3 . Observaram ainda que o organismo isolado do cão não é aglutinado pelo antisoro preparado com cepas lisas de $B$. abortus ou B. melitensis, mas o é pelo antisoro obtido com cepas rugosas de $B$. abortus, B. melitensis e B. ovis. Não verificaram ser as colônias rugosas mais sensíveis do que as lisas, à lise pela lisozima, e comprovaram os achados de DIAZ, JONES \& WILSON ${ }^{10}$, que demonstraram ser o antígeno superficial do germe isolado do cão, semelhante ao das colônias rugosas de $B$. abortus, $B$. melitensis e B. ovis. Estes autores propuseram a questão, se o microorganismo de origem canina deveria ser designado como Brucella suis biotipo 5 ou Brucella canis, preferindo os mesmos esta última, porque o germe não tem o antígeno lipopolissacarídico associado com o aglutinogênio liso e endotaxina existente nas amostras clássicas de Brucella e também por não utilizar o eritritol.

CARMICHAEL \& BRUNER ${ }^{5}$ caracterizaram morfológica, cultural e bioquimicamente o microorganismo isolado de tecidos de fetos caninos abortados, e o consideraram como causador de aborto e infertilidade em cadelas. Concluiram que o germe pertence ao gènero Brucella, baseados nas propriedades sorológicas, estudos de patogenicidade em pequenos animais de laboratório e análise dos produtos do metabolismo por cromatografia a gás.

CARMICHAEL e cols. ${ }^{4}$ relatam pela primeira vez, dois casos de infecção humana por acidentes de laboratório.

ROYER \& MC CULLOUGH ${ }^{23}$ fizeram estudos sobre a homologia do DNA de $B$. ovis, do microorganismo do aborto canino e de outras espécies de Brucella observando que o germe do aborto canino tem as seqüências de nucleotídeos semelhantes ao DNA da $B$. suis, e por inferência de dados prévios, à $B$. abortus, B. melitensis e $B$. neotomae.

De uma criação de cães "Beagles" infecta da por $B$. canis, MOORE, GUPTA \& CONNER ${ }^{33}$ conseguiram erradicar a infecção, eliminando os cães com diagnóstico bacteriológico positivo. Entre os restantes, apesar de $71 \%$ deles terem títulos aglutinantes de 1:100 ou 1:200, não conseguiram isolar a $B$. canis.

FAIGEL ${ }^{11}$ sugere chamar a brucelose canina de "febre dos Beagles". Observou que os filhotes que sobreviviam eram freqüentemente fracos e tendiam a apresentar linfadenopatia. Durante seus estudos, relata que dois indivíduos que trabalhavam no labora tório se infectaram, e três semanas após o contato, apresentaram uma doença semelhante à gripe, que durou várias semanas. Os pacientes apresentaram aumento dos linfonodos cervicais, febre baixa, suores no turros, mal estar e fadiga. De um dos indivfduos infectados foi isolado o agente do aborto canino, por hemocultura.

MOORE \& KAKUK ${ }^{34}$ realizaram estudos bacteriológicos, sorológicos e histológicos em cães infectados pela $B$. canis, com e sem bacteriemia, porém todos com soro-aglutinação positiva. Alguns dos cães bacteriêmicos se recuperaram espontaneamente, $e$ seus títulos aglutinantes diminuiram de $\mathbf{8 0 0}$ para 200. Os que permaneceram bacteriêmicos, mantiveram seus títulos de 800 . Os autores isolaram a $B$. canis da urina dos cães infectados e observaram que, como essa localização do germe não ocorre em fêmeas, - isolamento nos machos seria devido à proximidade da glândula prostática e ductos deferentes com a bexiga. 
MEYER ${ }^{28}$. ao contrário de todos os autores, conclui em seu trabalho que as Brucella isoladas de abortos caninos, são membros da espécie $B$. suis, sugerindo que sejam classificadas como Brucella suis biotipo 5 , e não como uma espécie separada. Contudo, como as amostras de Brucella canis são rugosas, não obteve nenhum dado consistente no teste de susceptibilidade das amostras ao fogo de Brucella.

MORRISSET \& SPINK ${ }^{35}$ relatam uma epizootia de aborto em um canil de "Beagles" com 178 animais, dos quais, os 37 filhotes não apresentaram evidência soro lógica ou bacteriológica de infecção, apesar de expostos a mães infectadas, e de ter sido encontrada a $B$. canis no colostro de um fêmea que havia abortado. Admitiram que esses filhotes não apresentaram infecção. porque foram separados da mãe logo depois de desmamados e antes dos 3 meses, pois a placenta canina tem 6 camadas e essa espessura impediria a passagem de imunoglobulinas e bactérias da circulação da mae para a do feto. Obsenaram que a bacteriemia pode ser demonstrada somente nos animais com títulos aglutinantes de 1:320 ou acima, e que a prova do 2-mercaptoetnol não podia ser usada para a detecção de anticorpos aglutinantes $7 \mathrm{~S}$, porque o aquecimento da combinação soromercaptoetanol a $50^{\circ} \mathrm{C}$. em seus testes, resultava na turvação do soro. Verificaram, ainda, que as aglutininas podem ser reveladas por um período de vários meses, $e$ isolaram o germe de tecidos $e$ sangue de animais aparentemente sadios, depois de um ano. Soros de animais infectados ou nao, pareciam nao ter nenhuma ação bactericida "in vitro" sobre a $B$. canis.

Observaram a doença em 2 pacientes humanos que trabalhavam no laboratório. Ambos apresentaram títulos aglutinantes de $1: 320$, e a $B$. canis foi isolada do sangue de um deles. A tetraciclina foi usada com êxito no tratamento.

MOORE ${ }^{30}$ numa revisão sucinta, relata que o único animal que apresenta infecção natural pela $B$. canis é o cão, e a maioria dos animais envolvidos pertence à raça "Beagle". mas a infecção também pode ser observada em outras raças como: Weimaraners, Foxhounds, Old English Sheepdogs, Pointers e Greyhounds.

DEYOE ${ }^{9}$ fez estudos sobre a patogenicidade do agente do aborto canino, inoculando cães e outras espécies de animais.
Comparou a infeccão por $B$. canis com a infeccão por $B$. suis em cães; a infeccão por $B$. canis foi caracterizada por grande número de microorganismos "in vitro", mas um período de incubação prolongado antes que se desenvolvessem alterações patológicas discemfreis, e a $B$. suis apresentou características opostas. $\mathrm{O}$ autor expôs bovinos, ovinos e surnos à B. canis por via conjuntival, para determinar sua susceptibilidade ao microorganismo, não verificando nenhum desenvolvimento de infeccão nas 6 novilhas prenhas testadas, mas observou ligeira elevação na resposta de anticorpos. Seis dentre doze suínos inoculados (fêmeas prenhes e machos sexualmente maduros) não deserv olveram infecção sistêmica, mas sim, infecção localizada nos linfonodos da cabeça. Sete dentre doze carneiros inoculados, apresentaram infecção sistêmica passageira. Efeitos clínicos ou patológicos de infecção por $B$. canis não foram observados em nenhuma das espécies testadas, concluindo o autor que é ocorrência rara a infecção transmissivel por esse microorganismo a outros animais domésticos além do cão. Verificou que a $B$. canis foi de baixa virulência para cobaias, em comparação com outras Brucella, e que macrófagos peritoniais de cobaias normais foram mais capazes de fagocitar e destruir $B$. canis que $B$. suis. Concluiu que a $B$. canis é distingüivel de outras brucelas lisas e rugosas, é um organismo distinto, causa uma doença específica em cães e tem um espectro limitado de infecciosidade.

HILL e cols. ${ }^{19}$, McCORMICK e cols. ${ }^{27} \mathrm{e}$ VAN HOOSIER e cols. ${ }^{44}$ realizaram estudos epizootológicos do aborto canino, focalizando os aspectos clínicos, medidas de controle, características da $B$. canis e resposta imune dos animais e das pessoas em contato com esse germe.

Uma revisão dos aspectos epizootológicos, diagnóstico e controle foi realizada por MOORE \& GUPTA ${ }^{32}$. O não isolamento de $B$. canis de animais com títulos de $1: 100$ e 1:200 e a observação de que alguns cães bacteriêmicos, depois de algum tempo tornam se abacteriêmicos, com diminuição concomitante do t/tulo de 1:c00 para 1:100 ou 1:200, levaram os autores a realizar experiências sobre o estado imune destes animais. Cães recuperados da doença ou com títulos aglutinantes sempre baixos foram infectados por via oral, com $10^{6}$ a $10^{10}$ células de $B$. canis. Somente um cão se 
infectou entre os doze com título baixo. Nenhum dos recuperados ${ }^{11}$ se infectou. Concluiram que aparentemente o estado imune era devido mais à imunidade celular do que humoral.

ANDERSON e cols. ${ }^{7}$ relatam um caso de infeccão humana pelo organismo do aborto canino em uma senhora. $\mathrm{O}$ microorganismo foi identificado como $B$. canis, tendo o soro da paciente fornecido um t/tulo de 1:250 para esse organismo. Verificaram posteriormente que a paciente havia sido infectada por um cão Pastor Alemão, de sua pro priedade, que deu um título de 1:500, e do qual foi isolado o mesmo germe.

HALL \& MANION ${ }^{17}$ estudaram 0 comportamento de 27 amostras de 6 es pécies de Bruce/la inclusive a $B$. canis, frente a vários antibióticos, tendo sido as tetraciclinais as mais eficientes.

MITRUKA \& ALEXANDER ${ }^{29}$ verifi. caram ser possivel a diferenciação da $B$. canis de outras espécies de Brucella por cromato grafia a gás.

GLEISER e cols ${ }^{14}$ estudaram as alterações patológicas em cães infectados por $B$. canis, e SHIFRINE e cols. ${ }^{39}$ estudaram a resposta de fetos caninos e neonatos, ao estímulo antigènico. Observaram que fetos infectados com B. canis no 50 9 dia gestação, e mortos 9 dias depois, demonstraram presença de anticorpos aglutinantes, indicando que se tornaram competentes para a produção de anticorpos no período próximo ao nascimento. A necrópsia, observaram extensa hiperplasia linforreticular no pulmão, baço, fígado e linfonodos. Reisolaram o microorganismo do pulmão e do fígado.

HALL ${ }^{16}$ acha que usualmente a infecção brucélica canina é restrita ao próprio cão, raramente podendo este funcionar como veículo de transmissão da infecção a outros animais domésticos ou ao homem. Relata que isolou 13 amostras de fagos de brucela, de fezes e coágulo sanguíneo de cães infectados com $B$. canis. Duas amostras de fagos lisaram 4 amostras de $B$. canis e uma de $B$. suis biotipo 5 . Tambem algumas amostras de $B$. abortus e $B$. neotomae foram lisadas, mas não as de $B$. melitensis.

LEWIS $^{25}$ fez uma pesquisa sorológica em 650 cães, para determinação de títulos aglutinantes para $B$. canis. Destes, 503 (77,4\%) deram títulos incompletos de 25 ou acima e $123(18,7 \%)$ deram títulos de 100 ou acima. Dos 3 grupos testados (mestiços, de raça pura e cães de caçal, os cães de caça revelaram maior percentagem de positividade com títulos de 1:100 ou acima $(299,9 \%) \mathrm{em}$ 64 cães, sendo a incidência em machos e fêmeas, semelhante. Os mestiços vieram em 2\% lugar, 13,6\% (47 cães) e em seguida os de raça pura, 13,2\% (12 cães). Supõese que a maior incidência da infecção em "Beagles" seja devida ao fato da criação dos mesmos em canis, em condições de confinamento, com constante entrada e saída de animais, bem como troca de reprodutores entre os diversos canis.

SWENSON, CARMICHAEL\& CUNDY ${ }^{40}$ relatam um caso de infecção humana em condições naturais (o 19 na opinião dos autores). A paciente parece ter adquirido a infecção de um cão (Pastor Alemão) do qual também se isolou a $B$. canis. Hemoculturas e soroaglutinações realizadas em 12 membros da famflia, forneceram resultados negativos. Os autores chamam a atenção para o achado não usual, de um cão infectado na comunidade, e não em condições de confinamento como é o caso das "Beagles", e como a famllia em questão não conhecia a história pregressa desse cão, concluem que talvez o mesmo tenha vivido antes em confinamento, tendo se infectado em algum canil e se tornado bacteriêmico por um prolongado período de tempo. Chamam também a atenção para o fato da ineficiência da antibioticoterapia na erradicação da infecção canina, enquanto que nos seres humanos, há um marcado contraste na aparente eficácia dos antibióticos nos poucos casos relatados e neste, sendo desconhecidas as razões para essa diferença.

PICKERJLL \& CARMICHAEL ${ }^{38}$ realizaram um programa de controle da brucelose canina em 2 canis comerciais na Pensilvânia $\mathbf{e}$ observaram o efeito dessa infecção na repro dução, que foi semelhante a de outras espécies infectadas com brucela, isto é, perdas por aborto e interferência com a reprodução.

PERCY, EGWU \& JONAS ${ }^{37}$ infectaram experimentalmente macacos (Macaca arctoides) com B. canis, por via oral e conjuntival, e intravenosa, obtendo culturas positivas de sangue duas semanas após a incubação, e títulos aglutinantes de 1:1.280. Lesões granulomatosas focais foram observadas nas vísceras e tecido linfoide.

LEWIS \& ANDERSON ${ }^{26}$ pesquisaram a 
incidência de aglutininas para $B$. canis em soros de militares (recrutas), num total de 1.208 indivíduos. 0 titulo de 1:100 ou acima foi considerado como "positivo". Entre os soros examinados, encontraram 5 positivos $(0,4 \%)$, sendo dois com títulos de 1:100, 2 apresentando títulos de 1:200 e um de 1:400. Não foi possivel aos autores conseguir registros clinicos desses indiv/. duos. Assim, nenhuma informação sobre a doença consta no trabalho. Este é o primeiro estudo feito na população humana, para verificação da presença de aglutininas para a B. canis e o fato de que $0,4 \%$ da população estudada tenha apresentado títulos significantes (1:100 ou acima) para $B$. canis, sugere que a incidência de brucelose humana clínica e subclínica, devida a esse microorganismo, é muito baixa. Entretanto, se a incidência de títulos significantes relatados é pequena, o mero fato de sua ocorrência pode ser de importância epidemiológica. Não puderam estabelecer se as pessoas estiveram expostas à B. canis, afirmando ainda que elas poderiam ter sido expostas a algum agente até agora desconhecido, que produziria uma reação cruzada com o antígeno de $B$. canis, produzindo, assim, um resultado falso positivo no teste de sono-aglutinação.

DAMP, CRUMRINE \& LEWIS $^{8}$ utilizaram para a pesquisa de aglutininas anti- $B$. canis, a prova em microplaca, verificando resultados semelhantes aos obtidos com o método de aglutinação em tubos, e que o micro teste fornece um meio econômico de seleção de soros positivos, usando-se uma quantidade mínima de equipamento, tempo, reagentes e soro.

HOFF \& NICHOLS ${ }^{21}$ realizaram inquérito sorológico visando à presença de aglutininas para $B$. canis em 274 cães apreendidos, 167 trabalhadores e 43 veterinários. Observaram que 10 cães $(3,65 \%)$ e um trabalhador $(0,59 \%)$, apresentaram títulos aglutinantes de 1:200 ou acima para B. canis. Entre os veterinários nenhum apresentou sorologia positiva para esse germe. Afirmam que embora a doença tenha sido reconhecível e controlável em canis, pouco é conhecido com relação à infecção por esse germe em cães de rua ou domésticos. Dos animais por eles testados, a maioria era mestiça.

HOFF e cols. ${ }^{20}$ pesquisaram aglutininas para B. canis nos soros de 770 animais silvestres $e$ apenas 5 (1 quati (raccon), 1 lince, 1 raposa vermelha e 2 coiotes) foram positivos na diluiç̧o de 1:200. Não realizaram tentativas de isolamento da Brucella.

$A$ presença da $B$. canis num canil, foi também observada por HARRIS e cols. ${ }^{18}$ nos EUA.

VON KRUEDENER ${ }^{46}$ na Alemanha, isalou $B$. canis de animais de uma criação de "Beagles" na qual havia ocorrência de aborto.

UEDA e cols. ${ }^{42}$ observaram em Tóquio, 3 casos de brucelose em cães com aglutininas anti-B. canis, com isolamento da mesma em todos os casos. UEDA e cols. $(1974)^{43}$, em outro trabalho, pesquisaram a $B$ canis em um canil, através de testes bacteriológicos e soralógicos, obtendo resultados positivos em todos eles.

GODOY e cols. ${ }^{15}$ observaram a ocorrência de $B$. canis no Brasil, através de provas sorológicas em soros caninos e humanos, tendo isolado a mesma de uma cadela com história de aborto recente.

GEORGE \& CARMICHAEL ${ }^{13}$ utilizaram com êxito, para o diagnóstico da brucelose canina por $B$. canis, um antígeno para método rápido (aglutinação em placa), preparado com uma cultura morta e corada de B. ovis.

HOFF \& SCHNEIDER 22 examinando 303 soros humanos, encontraram aglutininas anti-B. canis em 3, sendo que apenas em um. o título era significatio $(1: 400)$ e nos dois restantes o t/tulo era de 1:50.

VERGER e cols. ${ }^{45}$ isolaram em Mada gascar, de uma cadela com história de aborto e corrimento vaginal sanguíneo, em paralelo com culturas representativas de outras espécies Brucella. Foi colocada por suas características, no gênero Brucella; os autores são mais favoráveis à classificação do microorganismo isolado como Brucella suis biotipo 5 de acordo com MEYER (1969). Assinalam ainda que antes deste isolamento, a brucelose animal ou humana era desconhecida na ilha.

BLANKENSHIP, USAF \& SANFORD ${ }^{2}$ obsenaram um caso de infecção humana por B. canis, adquirida provavelmente por contato com um cão doente, caracterizado por febre intermitente e bacteriemia durante um periodo de quatro meses.

Em 1975, MUNFORD e cols. ${ }^{36}$ obser varam dois casos de brucelose humana por Brucella canis, adequiridos provaveimente por contato com cães domésticos infectados.

WEBER \& SCHLIESSER ${ }^{4}$ na Ale- 
manha, obtiveram num canil experimental, provas sorológicas positivas para B. canis, com titulos que variavam de 1:50 a 1:3.200, tendo isolado este microorganismo dos animais com títulos de 1:100 ou maiores.

CARMICHAEL \& GEORGE ${ }^{6}$ em breve revisão, apresentam as características morfo lógicas, clínicas, patológicas e epizootológicas da $B$. canis considerando também o problema dos testes sorológicos no diagnóstico da doença causada por esse microorganismo.

FLORES-CASTRO \& SEGURA 12 pesquisaram aglutininas para $B$. canis em 203 soros humanos e 500 soros caninos no México, observando títulos positivos (1:100 ou maiores) em $27(13,3 \%)$ dos soros hu. manos e em 140 (28,0\%) dos soros caninos. A Brucella canis foi isolada do sangue de 8 cães.

\section{CONCLUSOOES}

Foi feito levantamento bibliográfico da situação atual da brucelose canina e humana causada por Brucella canis, desde as observações iniciais de CARMICHAEL em $1966^{3}$. Até o momento, a $B$. canis foi identificada nos seguintes parses: Estados Unidos da América do Norte, Japão, Alemanha Ocidental, llha de Madagascar, Brasil e México.

\section{REFERENCIAS BIBLIOGRAFICAS}

1. ANDERSON, T.G.; BERNHARDT, E.: CUNDY, K.R.; SWENSON, R.M.; CARMICHAEL, L.E.; WERRIN, M.; SCHRACK JR., W.D.; WITTE, E.J.; COCKIN, J.R. \& BROWN, G.M., Human infection with the organism of canine abortion. Morbidity and Mortality. Weekly Report, 19 (23):224-225, 1970.

2. B LANKENSHIP, R.M.; USAF, LT COL; SANFORD, J.P., Brucel/a canis. A cause of Undulant Fever. Am. J. Med., 59 (3) :424-426, 1975.

3. CARMICHAEL, L.E. Abortion in 200 Beagles. (News Report). J. Am. Vet. Med. Assoc., 149:1126, 1966.

4. BAROL, S.R.; BROAD, R.H. \& FREITAG, J.L. Human infection with the agent of abortion. Morbidity and Martality. Weekly Report, 17:286, 1968. 5. \& BRUNER, D.W. Characteristics of a newly recognized Brucella species responsible for infections canine abortions. Cornell Vet., 58:579-592, 1968.

6.

\& GEORGE, L.W. Canine Brucellosis: Newer krowledge - International Symposium on Brucellosis (11), Rabat. Develop. biol. Standard, Vol. 31, pp. 237-250 (S. Karger, Basel, 1976), 1975

7.

\& KENNEY, R.M. Canine abortion caused by Brucella canis. $J$. Am. Vet. Med. Assoc., 152:605616, 1968.
8. DAMP, S.C.; CRUMRINE, M.H. \& LEWIS JR., G.E. Microtiter Plate Agglutination Test for Brucella canis antibodies. Appl. Microbiol., 25:482-490, 1973.

9. DEYOE, B.L. Studies on the pathogenesis of a canine abortion agent (B. canis) in dogs and other animals. Ames, Jowa State University, Ph. D. Thesis, 1970.

10. DIAZ, R.; JONES, L.M. \& WILSON, J.B. Antigenic relationship of Gram negative organism causing canine abortion to smooth and rough Brucellae. J. Bacteriol, 95:618624, 1968.

11. FAIGEL, H.C. Beagle Fever - Canine Brucellosis - Clin. Pediatr., 859, 1969.

12. FLORES-CASTRO, R. \& SEGURA, R. $A$ serological and bacteriological survey of canine brucellosis in Mexico. Cornell Vet., 66 347-352, 1976.

13. GEORGE, L.W. \& CARMICHAEL, L.E. A plate agglutination test for the rapid diagnosis of Canine Brucellosis. Am. J. Vet. Res., 35 (7):905-909, 1974.

14. GLEISER, C.A.; SHELDON, W.G.; VAN HOOSJER, G.L. \& HILL, W.A. Pathogenic changes in dogs infected with a Brucella organism. Lab. Anim. Sci., 21 (4) :540-545, 1971.

15 GODOY, A.M.; PERES, J.N. \& BARG, $L$ Ocorrência da Brucella canis no Brasil. Anais do $V$ Congresso Brasileiro de Microbiologia, pág 77-78, 1974.

16. HALL, W.H., Editorial - Epidemic bru- 
cellosis in Beagles. J. Infect. Dis., 124:616-618, 1971.

17. \& MANJON, R.E. In vitro susceptibility of Brucella to various antibiotics. Appl. Microbial., 20:600-604. 1970.

18. HARRIS, A.M.; HORTON, M.L.; LETSCHER, R.M.; McCONNELL, E.E. \& NEW, A.E. Enzootic Brucella canis: An occult disease in a research canine colony. Lab. Anim. Sci., 24 (5):796-799. Apud: et al. 1975. Microbiol. Abstr., 59 (4):2191, 1974.

19. HILL, W.A.; VAN HOOSJER, G.L \& McCORMICK, N. Enzootic abortion in a canine production colony - 1 - Epizootiology, clinical features and control procedures. Lab. Anim. Care. 20:205-208, 1970.

20. HOOF, G.L; BIGLER, W.J.; TRAINER, D.O.; DEBBIE, J.G.; BROWN, G.M.; WINKLER, W.G.; RICHARDS, S.H. \& REARDON, M. Survey of carnivore and opossum sera agglutinins to Brucella canis. J. Am. Vet. Med. Assoc., 165:830-831, 1974.

21. _._. \& NICHOLS, J.B. Canine Bru cellosis in Florida"Serological survey of pound dogs, animal shelter workers and veterinarians. Am. J. Epdemiol., 100 (1):35-39, 1974.

22. __. \& SCHENEIDER, N.J. Serolo gical survey for agglutinins to Brucella canis in Florida residents. Am. J. Trop. Med. Hyg., 24 (1):151, 1975.

23. HOYER, B.H. \& McCULLOUGH, N.B. Homologies of deoxiribonucleic acids from Brucella ovis; canine abortion orga nisms and other Brucella 'species. J. Bacterial., 96:1783-1789, 1968.

24. JONES, L.M.; ZANARDO, M.; LEONG, D. \& WILSON, J.B. Taxonomic position in the genus Brucella of the causative agent of canine abortion. J. Bacteriol., 95:625-630, 1960.

25. LEWIS, G.E. A serologic survey of 650 dogs to detect titers for Brucella canis. J. Anim. Hosp. Assoc., 8:102-107, 1972.

26. \& ANDERSON, J.K. The inci-

dence of Brucella canis antibodies in sera of military recruits. Am. J. Public Health, 63 (3):204, 1973.

27. MCCORMICK, N.; HILL W.A.; VAN HOOSJER JR., G.L. \& WENDE, R. Enzootic abortion in a canine production colony. 2 - Characteristics of the associated organism evidence for its classifications as Brucella canis, and antibody study on exposed humans. Lab. Anim. Care, 20:209-214, 1970.

28. MEYER, M.E. Brucella organises isolated from dogs: Comparison of characteristics of members of the Genus Brucella. Am. J. Vet. Res, 30:1751-1756, 1969.

29. MITRUKA, B.M. \& ALEXANDER, $M$. Differentiation of Brucella canis from other brucella by gas cromatography. Appl. Microbiol., 20 (4):649650, 1970.

30. MOORE, J.A. Brucella canis infection in dogs. J. Am. Vet. Med. Assoc., 155:2034-2052, 1969.

31. \& BENNETT, M.A. A previously undescribed organism associated with canine abortions. Vet. Rec., 80:604605, 1967.

32. _ \& GUPTA, B.N. Epizootiology, diagnosis and control of Brucella canis. J. Am. Vet. Med. Assoc., 156:1737-1740, 1970.

33. \& CONNER, G.H. Erradication of $B$. canis from a dog colony. J. Am. Vet. Med. Assoc., 153:523-527, 1968

34. \& KAKUK, T.J. Male dogs naturally infected with Brucella canis. J. Am. Vet. Med. Assoc., 155:1352-1358, 1969.

35. MORRISSET, R. \& SPINK, W.W. Epidemic canine brucellosis due to a new species, Brucella canis. Lancet, 2:1000-1002, 1969.

36. MUNFORD, R.S.: WEAVER, R.E.; PATTON, C.; FEELEY, J.C. \& FELDMAN, R.A., Human disease caused by Brucella canis: A clinical and epidemiological study of two cases. J. Am. Med. Assoc., 231 (12):1267-1269. Apud: et al. 1975. Microbiol. Abstr. 60 (1):323, 1975.

37. PERCY, D.H.; EGWU, J.N. \& JONAS, A.M. Experimental Brucella canis infection in the monkey (Macaca arctoides). Can. J. Camp. Med., 36 (3) :221-225, 1972.

38. PICKERJLL, P.A. \& CARMICHAEL. L.E. Canine Brucellosis. Control pro grams in commercial kenneis and effect on reproduction. J. Am. Vet. Med. Assoc., 160:1607-1615, 1972.

39. SHIFRINE, M.; SMITH, J.B.;BULGIN. M.S.; BRYANT, B.J.; ZEE, YUAN. 
CHANG \& OSBURN, B.J. Response of canine fetuses and neonates to antigenic stimulation. J. Immunol., 107 (4):965-970, 1971.

40. SWENSON, R.M.; CARMICHAEL, L.E. \& CUNDY, K.R. Human infection with Brucella canis. Ann. Intem. Med., 76 (3) :435-438, 1972.

41. TAUL, LK.; POWELL, H.S. \& BAKER, O.E. Canine abortion due to an unclassified Gram-negative bacterium Vet Med. Small Anim. Clin., 73:543-544, 1967.

42. UEDA, K.; SAEGUSA, J.; FUGIWARA, K.; MUTO, S.; OKADA, K.; HASEGUA, A.; SAEGUSA, S. \& USUI, K. Detection of Brucella canis infection in dogs from Tokio area. Jap. J. Vet Sci., 36 (6):539-542. Apud: et al. 1975. Microbiol. Abstr. (B), $10(6): 10 \mathrm{~B} 6776$, 1974.

43. UEDA, K.; MAGARIBUCHI, T.; SAEGUSA, J.; URANO, T.; ITOH, K.; KIUCHI, Y. \& FUGIWARA, K. Spontaneous Brucel/a canis infection in beagles: Bacteriological and serological studies. JPN. J. Vet. Sci., 36 (5):381-390. Apud: et al. 1975. Microbiol. Abstr., 60 (1):326, 1974

44. VAN HOOSJER, G.L; McCORMICK, N. \& HILL, W.A. Enzootic abortion in a canine production colony: 3 - Bacteriemia, antibody response and Mercaptoetanol sensitivity of agglutinins. Lab. Anim. Care, 20:964 968, 1970.

45. VERGER, J.M.; CATE, M.; CHATELAIN, R.; RAMISSE, J. \& BLANCOU, J. Isolement de Brucella suis biotype 5 à Madagascar, chez une chienne. Validity du nom d'espece Brucella canis. Ann. Microbiol. (Grance). 126 A:57-74, 1975.

46. VON KRUEDENER, R.B. Isolienung und bestimmung von Brucella canis aus einem Beaglebestitand. Zentralbl. Veterinaermed. (B), 21:307-310, 1974.

47. WEBER, A. \& SCHLJESSER, T. Serological and cultural demonstration of Brucella canis in beagles in an experimental kennel. Zentralbl. Veterinaermed, Reihe B, 22 (5):403-410. Apud: _t al. 1976. Microbiol. Abstr., 61 (2):900, 1975. 